\title{
Differential air/fresh charge demand, supply and utilisation in two-stroke spark ignition engines
}

\author{
M. N. Lawal ${ }^{1}$, M. S. Abolarin ${ }^{2}$, A. Nasir ${ }^{2 *}$ and A. N. Musa ${ }^{2}$ \\ ${ }^{1}$ Faculty of Engineering, University of Abuja, \\ Federal Capital Territory, Abuja Nigeria \\ Email: nasir.lawal@uniabuja.edu.ng \\ Phone: +2347031621199 \\ ${ }^{2}$ School of Engineering and Engineering Technology \\ FUT - Minna, Niger State Nigeria \\ *E-mail: a.nasir@futminna.edu.ng \\ Phone: +2348033183561
}

\begin{abstract}
In a two-stroke engine, the net quantity of air/fuel delivered to the cylinder is usually less than that demanded amount due to flow constraints, the nature of working fluid, port timings and pressure waves. Central to all these losses is the limited time for combustion relative to the intake ports' open down periods. This research utilises a manifold differential-pressure model to establish a loss of fresh-charge due to the supply time-lag and cycle-overlaps which are chiefly dependent on the ports' positions and engine speeds. Three different throttle angles and engine speeds were utilised to establish differential flow rates between the ports' opening and closing intervals. Test results show that at low intake pressure and engine speed, $12.5 \mathrm{~ms}$ is required to fulfil the engine demand with a maximum value of $16.5 \mathrm{~g} / \mathrm{s}$ occurring at $4 \mathrm{~ms}$. The corresponding supply is $5.5 \mathrm{~g} / \mathrm{s}$ lagging by about $7.5 \mathrm{~ms}$ and resulting in a maximum loss of $13 \mathrm{~g} / \mathrm{s}$. At high speed with the same initial pressure, the maximum demand of 40 $\mathrm{g} / \mathrm{s}$ occurs at $2.5 \mathrm{~ms}$ while the maximum supply of $32.5 \mathrm{~g} / \mathrm{s}$ lags behind by $5 \mathrm{~ms}$, resulting in a maximum loss of $22.5 \mathrm{~g} / \mathrm{s}$. Thus, the differential pressure model is a useful tool for estimating the difference between the charge demanded and that supplied.
\end{abstract}

Keywords: Fresh charge; demand; supply; utilisation.

\section{INTRODUCTION}

The quantity of air/fuel delivered to the cylinder of an internal combustion engine (ICE) is a major determinant of its power output. In two-stroke engines, the quantity of the air/fuel charge is delivered to the crankcase and hence, the quantity supplied to the combustion chamber is usually far less than that required due to system constraints, the nature of the working fluid, port timing and pressure waves. The manifold system where the charge is momentarily stored for better performance and safer operation is responsible for a large portion of the shortfall [1,2]. From the engine demand point of view, the quantity of fresh charge for maximum performance is dependent on two parameters - engine capacity and type of fuel employed [1]. In two-stroke engines, the engine capacity is further limited by the presence of intake and exhaust ports. As the inlet manifold draws in air/fuel into the crankcase during the engine compression stroke, 
the transfer port (TP) is closed, while intake port (IP) is opened down. In-flow is achieved by a vacuum pumping effect of the crankcase case during the upward stroke of the piston. The open down of the IP lasts for a fraction of the upward stroke and is slightly beyond the top dead center (TDC) - this refers to the open down period (ODP) of the IP. As the IP closes, the flow is redirected away from the port and towards the throttle inlet [3]. This reversal of flow causes a pressure drop which continues until the manifold pressure is below that of the atmospheric pressure in the vicinity of the IP. The drastic drop in pressure results in a vacuum pump-in of air/fuel with varying instantaneous values. The process is repeated several times over a short period of time, thereby setting an oscillation into the flow within the manifold [4]. The pressure at the low level in the supply line causes the inflow of air/fuel to charge into the manifold and continue to increase until it reaches a high-level above atmospheric value. During the ODP of IP, the high level pressure pushes the supply charge into the crankcase/cylinder. However, there is usually a significant loss in charge as it flows past the IP majorly due to supply pressure rate against port timing. Manifold differential pressure (MDP) is the pressure rate of growth or fall within the manifold during mass transfer across its boundary over a portion of an engine cycle. Mass transfer into the crankcase/cylinder is only possible during the open down period of the IP [4]. Within this period, mass transfer increases from zero to a maximum value, and later diminishes gradually to a constant supply level. For a perfect operation, the charge demanded by the engine and that delivered at the same time must be the same. However, the operation of the IP causes part of the supply to not be delivered. In carburettor engines, the supply charge is a mixture of air and fuel; while in direct injection engines (DIEs), the supply charge is air. In either case, the power output of the engine is highly reduced. While it causes irregular operations, incomplete combustion and cycle overlap in carburettor systems retai original, it also results in inadequate air supply with the non-proportionate high presence of fuel against engine demand in DIE systems [5]. This non-proportionate supply is a general situation in two stroke engines as it also affects biofuels. Each respective fuel class' property changes the combustion and performance characteristics, especially that of biodiesel compared to diesel [6-9].

The control of stoichiometric air flow during transient operations has been a strong area of interest in the design domain [10]. The two methods that are commonly used in this respect are the conventional air mass sensor and the speed density methods. The latter method is less accurate but mostly used by manufacturers due to the high costs and less durability of the former. In all cases, the intent is to determine the quantity of air that is being supplied. In the quest for a solution, different flow parameters had been utilised. A Laser Doppler Anemometry (LDA) under motored conditions at low engine speeds had been used to provide information about the ensemble's average and in-cycle axial and radial velocities at various spatial locations within the manifold. Observation shows that after BDC of induction stroke, a backflow from individual branches occurs, indicating the inadequacy of flow inertia to sustain induction at low speeds, thus lots of the supply charge were not delivered[10, 11]. A cylinder combustion pressure signal sensor has also been used as an alternative inlet air flow sensor with the aid of soft-computing techniques that utilise pressure variation to evaluate the inlet of mass air flow without significant loss in precision [10].

Several possibilities have been identified as means of improving air supply to the cylinder of a spark ignition engine. One of such is the supply of addition power during the drive train by injecting air directly into the combustion chamber using an additional valve placed in the cylinder head. This, however, requires extensive and 
costly modifications [12]. Another stride in development was the optimisation of intake venturi type restrictor in a Formula SAE car which was conducted to allow the maximum possible flow rate to the engine by reducing the pressure difference across the venture at all speeds. CDF were used to evaluate the minimum pressure drop that will allow a maximum flow rate achieved using the converging and diverging angles of 12 degrees and 6 degrees respectively, resulting to over 5\% improvement [13]. Despite this achievement, it was observed that attention was placed only on the loss across the intake into the manifold without consideration for time of delivery and valve openings.

Turbocharging has also been adopted as a means of improving charge supply. In this regard, Norbert et al.[14], presented a study on the intake manifold boosting of turbocharged spark ignition engines in which he showed that the combination of downsizing and turbocharging is an excellent approach for managing fuel economy with maximum power output retention. It was however pointed out that a substantial loss in drivability is eminent due to the occurrence of turbo-lag phenomena. A turbo valve was therefore utilised to supply air to the manifold to overcome the lag. Thus, at excessively high speeds, part of the air supplied is not available for combustion. The study further demonstrated that for a load step at $2000 \mathrm{rpm}$, the rise time was drastically reseeded from $2.8 \mathrm{~s}$ to as low as $1.24 \mathrm{~s}$. To keep the air supply for combustion close enough to the quantity demanded by the engine, another study had developed a switching low pressure valve (LPV) controller to intermittently switch off fuel supply when the air supply is out of range of the predetermined air/fuel ratio table within a very short time [15]. This development however faced issues of maintenance at high temperatures and sensitivity as feedback is taken directly from the engine's operation in real time. The use of a lookup table in engine control units (ECU) incorporated with a proportional integral controller (PIC), a feed-forward and feed-back control scheme for effective engine management system (EMS) is another step-up in air/fuel throughput management. It involves the tracking of engine speed command and the regulation of air/fuel ratio which are simultaneously achieved under the multi-input multi-output (MIMO) approach based on the model predictive control systems (MPCS)[16]. The result shows that the combined operations of PIC, MIMO and MPCS have significantly minimised the gap between supply and engine demand. However, this gain is predominantly based on ideal operations in the early part of the engine's life, with little or no attention to wear and the variation of system physical dimensions, which usually result in higher emissions as the engine ages. Emission in two stroke engines, particularly that from diesel engines, is a major environmental concern. While this research deals with spark ignition engines, it is opined [17] that the diesel engine operates in a dual fuel mode and can give improved emissions with enhanced brake thermal efficiency in comparison to that of a normal running mode.

The progressive interest of engine designers is in the development of costeffective environmental friendly engines. This is better achieved with an accurate measurement of the charge supplied to the combustion chamber. In a two-stroke engine, part of the charge supplied is restricted at the intake port due to the supply time-lag and overlap resulting from port timing relative to engine speed. The resultant effect leads to incomplete combustion and hence lower power output, environmental pollution and poor fuel economy. Despite numerous studies conducted on air/fuel supply chain systems to bring combustion much closer to the stoichiometric state, the quantity of supplied charge lost to time-lag and overlap resulting from port timing remains unbridged. Therefore, this research work concentrates entirely on the estimation of charge loss due to port timing. The present paper emphasises the use of a manifold 
differential pressure model to determine the instantaneous air/fuel supply at different throttle angles and engine speeds in a two-stroke SIE. It also compares the results against engine demand under the same operating conditions with the aim of establishing the amount of loss based on pressure drop.

The study is significant as it helps improve the air/charge demand and supply of a spark ignition engine by utilising manifold differential pressure and the time lag of supply. Theoretically, it also establishes an instantaneous mass transfer audit system that could be utilised as feedback control elements in the supply chain. Finally, reducing lag-time and eliminating overlaps provide better air/fuel ratio and improve the performance of SIEs which also depend on the fuel properties, particularly density, viscosity, calorific value, flash and pour points[18].

\section{MATERIAL AND METHODS}

\section{Materials and Components}

The basic component parts of the two-stroke SIE used is presented schematically in Figure 1. The fuel supply and metering system - the carburettor receives and measures the airflow and delivers the predetermined quantity of fuel to keep the mixture in the proper range and mix the two finely and evenly.

i. The metering rate of the carburettor is $1.5 \mathrm{~g} / \mathrm{s} \pm 1 \%$ with a vertically aligned valve disc diameter of $0.0357 \mathrm{~m}$. Air passes through the valve opening and get mixed with a fuel supply from a tube opening located close to air inlet side. A narrow kink is provided to speed up air flow which results in a high pressure drop, thus resulting in a pumping effect that draws in air/fuel at a ratio of about 1:15.

ii. The intake manifold momentarily stores the charge received and supplied to the crankcase due to pressure variation. The throughput capacity is $85 \mathrm{~g} / \mathrm{s} \pm 15 \%$ variance with an effective length of about $23 \mathrm{~cm}$ and an average diameter of approximately that of the carburettor at $3.57 \mathrm{~cm}$.

iii. Ashcroft Manifold Pressure Gauge with a resolution of 0.02 bar and sensitivity of 5. It utilises a Burdon tube incorporated with a hairspring and rotary mechanism to effect the required deflection as indicated linearly with a pointer over a calibrated scale with 0.02 resolution and an overall accuracy of $0.2 \%$.

iv. System control unit equipped with a Grill-AF120 supply controller that operates based on a predetermined Air/Fuel ratio table (14.7/1 for SIE). The device is a simple set-point technology utilising a $4-20 \mathrm{~mA}$ output signal range to drive fuel pumps and pneumatic valves in turbo engines.

v. Fuel supply pump - utilises a STANLI SOL model GSS340 12 v-Amps with an average flow rate of $1.25 \mathrm{~g} / \mathrm{s}$ fuel supply to a carburettor assisted with gravity and a vacuum pumping effect.

vi. Crankcase - a large flask of approximately $37.5 \mathrm{cl}$ equipped with two mass transfer ports. The intake port (IP) is linked to the manifold and controlled by a read valve and port timing based on the engine speed. At the top side is the transfer port lined to the combustion chamber. Effective crankcase to cylinder volume ratio is 1.45.

vii. Combustion chamber - with a bore of $0.07396 \mathrm{~m}$, a stroke of $0.07548 \mathrm{~m}$, a spark advance of $26^{\circ}$, a combustion duration of $56^{\circ}$, maximum speed of $9000 \mathrm{rpm}$ and maximum operating pressure and temperature of 25.9 and $1972 \mathrm{~K}$ respectively. An SAE30 lubricant pre-mixed $8 \%$ per litre of petrol is employed.

viii. Inlet port and outlet port timing - angles are $48^{\circ}$ bTDC and $48^{\circ}$ aTDC respectively. 


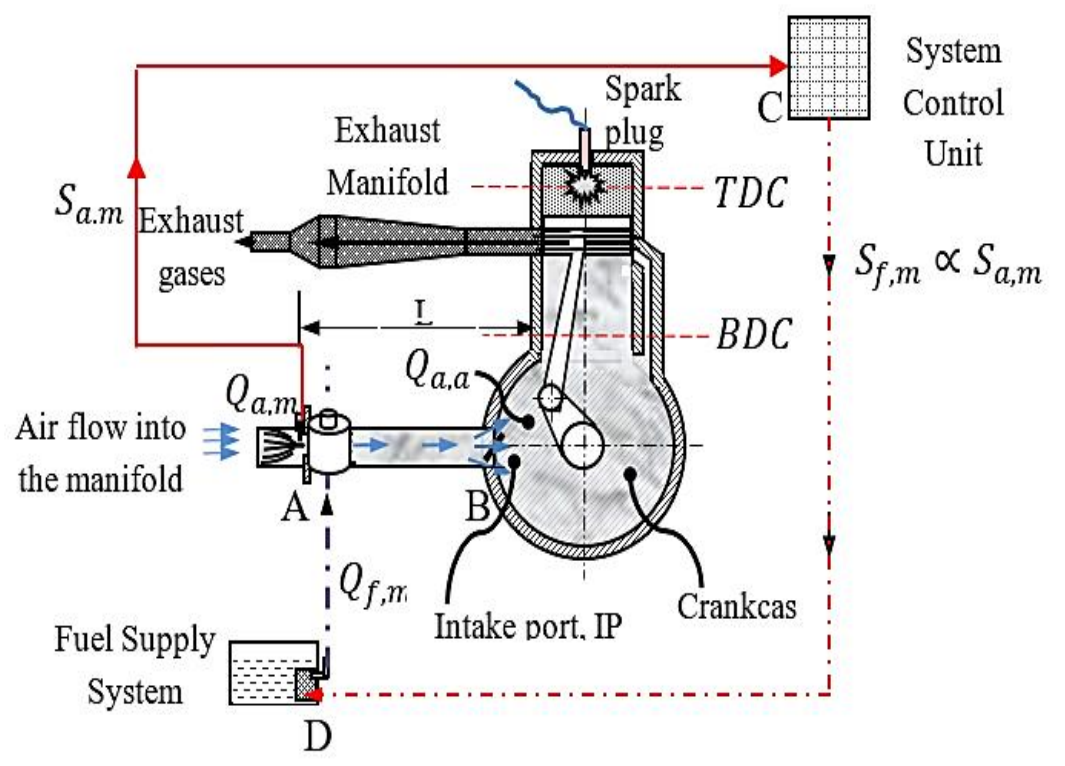

Figure 1. Schematic diagram of mass and information transfer in a two-stroke SIE.

\section{Model Concept and Method}

From the schematic model diagram in Figure 1, the quantity of air, $\mathrm{Q}_{\mathrm{a} . \mathrm{m}}$, entering the manifold is measured using an anemometer at point A. A voltage signal proportional to the energy contained in the air/fuel is generated and sent to the control unit (CU) at $\mathrm{C}$. Qa.m. After crossing the throttle constraint, it is made to travel through the manifold of length, $\mathrm{L}$ to intake port, IP at B and finally into the crankcase. Part of $\mathrm{Q}_{\mathrm{a} . \mathrm{m}}$ is not delivered on arrival due to port closure. The quantity $\mathrm{Q}_{\mathrm{a}, \mathrm{a}}$, is delivered to the crankcase and hence is significantly less in the cylinder. However, the input information arriving at $\mathrm{C}$ from $\mathrm{A}$ is a signal, $\mathrm{S}_{\mathrm{a}, \mathrm{m}}$ which is equivalent to $\mathrm{Q}_{\mathrm{a} . \mathrm{m}}$. The control unit at $\mathrm{C}$ processed it and gave out an output signal, $S_{\mathrm{f}, \mathrm{m}}$ based on a look-up table of predetermined sets of air-fuel ratio. Finally, it ordered the fuel pump actuator at $\mathrm{D}$ to supply the quantity $\mathrm{Q}_{\mathrm{f}, \mathrm{m}}$ of fuel for combustion. This quantity, $\mathrm{Q}_{\mathrm{f}, \mathrm{m}}$ is proportional to $\mathrm{Q}_{\mathrm{a} . \mathrm{m}}$. However, the difference in air flow $\mathrm{Q}_{\mathrm{a} . \mathrm{m}}-\mathrm{Q}_{\mathrm{a}, \mathrm{a}}$, results in a proportionate difference in fuel supplied. Thus, during combustion, $Q_{a . m}-Q_{a, a}$ of air is absent while its equivalent quantity of fuel is present. It will not participate in the combustion process and therefore will come out through the exhaust as unburned gases and waste in general.

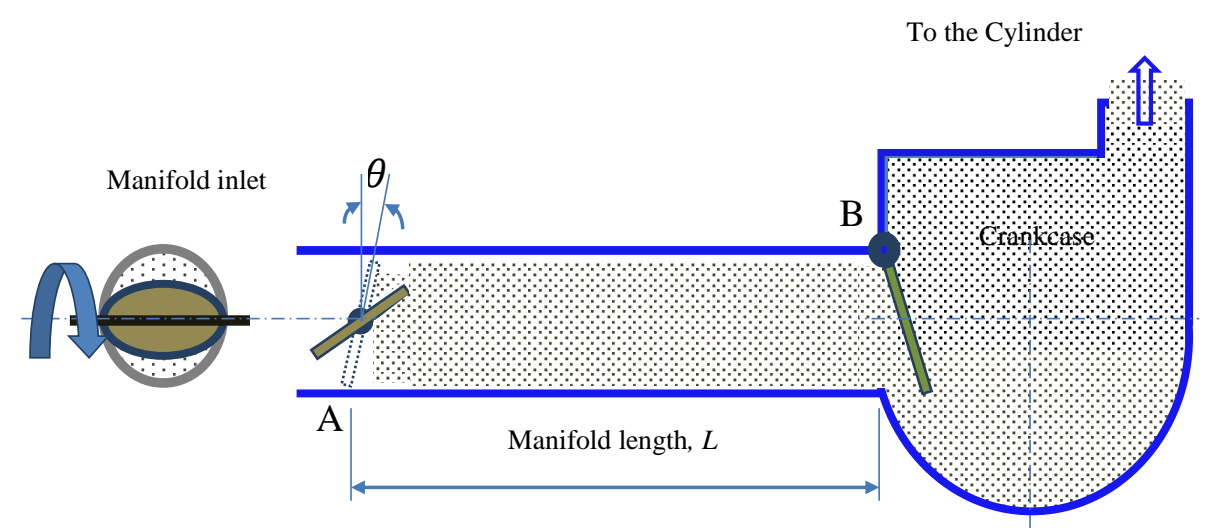

Figure 2. Intake manifold with intake port into the crankcase. 
Figure 2 presents the control volume of the manifold and crankcase. The variable throttle angle provides the required projected flow area. Air/charges enter at A and moves to the crankcase via B. Only a fraction of the charges aspirated is delivered before the inlet valve IV at B closes.

The charge mixture flow demanded is a function of swept volume, engine speed $N$, and air-fuel mixture density, given as [19]:

$$
\sum \dot{m}_{m, c}=\rho_{m i x} V_{s} N
$$

The mixture density is obtained from a weighted average of the densities of air and fuel supply and their corresponding mass fractions, defined as [20]:

$$
\rho_{\text {mix }}=\frac{\rho_{a} \rho_{f}}{Y_{f} \rho_{a}+Y_{a} \rho_{f}}
$$

The supplied quantity through the crescent openings of the throttle valve travel a distance $\mathrm{L}$ as shown in Figure 2 and passes through the IP into the crankcase with a net rate given by [20]:

$$
\begin{aligned}
& \dot{m}_{S, c}=C_{D} * A(\varphi) * \frac{P_{a}}{\sqrt{R T_{a}}}\left(\frac{P_{m}}{P_{a}}\right)^{\frac{1}{K}} \sqrt{\frac{2 K}{K-1}\left[1-\left(\frac{P_{m}}{P_{a}}\right)^{\frac{K-1}{K}}\right]} \text { for } \mathrm{p}_{\mathrm{m}} / \mathrm{p}_{\mathrm{a}}<1 \\
& \dot{m}_{S, c}=C_{D} * A(\varphi) * \frac{P_{a}}{\sqrt{R T_{a}}} K^{\frac{1}{2}}\left(\frac{2}{K+1}\right)^{\frac{(K+1)}{2(K-1)}} \quad \text { for } \mathrm{p}_{\mathrm{m}} / \mathrm{p}_{\mathrm{a}} \geq 1
\end{aligned}
$$

The area input variable in Equation (2) is evaluated for each throttle angle using the Heywood expression for two-half crescent openings, calculated as [9]:

$$
\begin{gathered}
A(\varphi)=-\frac{d D}{2}\left[1-\left(\frac{d}{D}\right)^{2}\right]^{\frac{1}{2}}+\frac{d D}{2}\left[1-\left(\frac{d}{D} \frac{\cos \varphi_{o}}{\cos \left(\varphi_{o}+\varphi\right)}\right)^{2}\right]^{\frac{1}{2}}+\frac{D^{2}}{2} \sin ^{-1}\left(\left[1-\left(\frac{d}{D}\right)^{2}\right]^{\frac{1}{2}}\right) \\
-\frac{D^{2}}{2} \frac{\cos \left(\varphi_{o}+\varphi\right)}{\cos \varphi_{o}} \sin ^{-1}\left(\left[1-\left(\frac{d}{D} \frac{\cos \varphi_{o}}{\cos \left(\varphi_{o}+\varphi\right)}\right)^{2}\right]^{\frac{1}{2}}\right), \\
\text { for } \varphi<\left[\cos ^{-1}\left(\frac{d}{D}-\cos \varphi_{o}\right)-\varphi_{o}\right]
\end{gathered}
$$

As $\varphi \rightarrow 90^{\circ}$, Equation (6) is used for a better result.

$$
\begin{array}{r}
A(\varphi)=-\frac{d D}{2}\left[1-\left(\frac{d}{D}\right)^{2}\right]^{\frac{1}{2}}+\frac{D^{2}}{2} \sin ^{-1}\left(\left[1-\left(\frac{d}{D}\right)^{2}\right]^{\frac{1}{2}}\right) \\
\text { for } \varphi \geq\left[\cos ^{-1}\left(\frac{d}{D}-\cos \varphi_{o}\right)-\varphi_{o}\right]
\end{array}
$$

The mass of air/fuel that eventually arrives in the cylinder is given by [19]:

$$
\dot{m}_{a, c}=\frac{p_{m}}{R T_{m}} * \eta_{d} * c_{o} \omega=\frac{\eta_{d} \rho_{a, m} V_{s} N}{2}
$$


The rate of pressure growth in the manifold is expressed as [21]:

$$
\dot{p}_{m}=\frac{R T_{m}}{V_{m}} * A(\varphi) p_{a} C_{D} \sqrt{\frac{2}{\beta R T_{a}}} * \sqrt{\left(\frac{p_{m}}{p_{a}}\right)^{\alpha}-\left(\frac{p_{m}}{p_{a}}\right)^{\xi}}-c_{o} \eta_{d} \omega p_{m}
$$

Where $\beta=(K-1) / K, \propto=2 / K, \xi=(K+1) / K$

The net rate of fuel demanded but not supplied due to the blockage of ports is [20]:

$$
\Delta Q_{f}=\frac{1}{14.7} \Delta Q_{a}=\frac{1}{14.7}\left(Q_{a, m}-Q_{c y l .}\right)
$$

Other supporting theories of compressible flow in pipes include friction and compressibility relations given in literatures [2, 21, 22].

\section{EXPERIMENTAL SETUP}

\section{Design of Experiment}

The experiment was designed to measure the flow variables of air/fuel charge through the supply chain systems which include an air cleaner, air dryer, throttle valve, manifold cylindrical container and inlet to the crankcase/cylinder. The air cleaner, dryer and throttle valve were considered as a lumped unit with a discharge coefficient of $58.2 \%$. The manifold diameter and length were considered to be approximately equal to those of TD 110 single cylinder two-stroke SIE with an assumed ideal straight flow path. Losses along the length are considered to be influenced by the nature of the working fluid as it flows past the walls of the manifold, and flow is assumed to be uniform. The open down period was determined by the intake port angle and the engine speed. At a given intake pressure with the throttle angle and engine speed as inputs, the pressure growth and mass flow rate of charges into and out of the manifold were used as outputs to estimate the losses.

\section{Experimental Procedure}

The engine was first run for about 10 minutes to attain steady working conditions with the dynamometer set to zero load. The rate of fuel consumption, flow rate of air to the engine and corresponding temperatures were recorded. The throttle plate lever was then adjusted until the engine speed was approximately $1000 \mathrm{rpm}$ which correspond to a $30^{\circ}$ throttle angle. The manifold pressure variation over each cycle for 2 minutes was recorded and the average values of the pressure and flow rate into the crankcase/cylinder for 2,000 cycles were estimated. The processes were repeated for engine speeds of $4000 \mathrm{rpm}$ and $7000 \mathrm{rpm}$ at corresponding throttle angles of $60^{\circ}$ and $75^{\circ}$ respectively. The value of the discharge coefficient which is a function of flow area, Reynolds and Mach numbers was determined by measuring the pressure upstream and downstream of the throttle plate. The manifold absolute pressure sensor was used to measure the manifold pressure and the pressure in the cylinder was measured using a piezoelectric pressure sensor. Temperature of air at intake and that inside the manifold were measured using an intake thermometer and the manifold absolute temperature sensor respectively. The mass flow rate into the inlet manifold and the engine speed were measured using the air mass and engine crank position sensors respectively. In each case, the intake pressure was returned to $0.104 \mathrm{MPa}$ and the throttle position 
adjusted until the required speed was attained and the engine made to run steadily. The pressure growth and flow rates over each cycle and their average estimate for two minutes evaluated against each speed and their corresponding open down periods of IPs were measured.

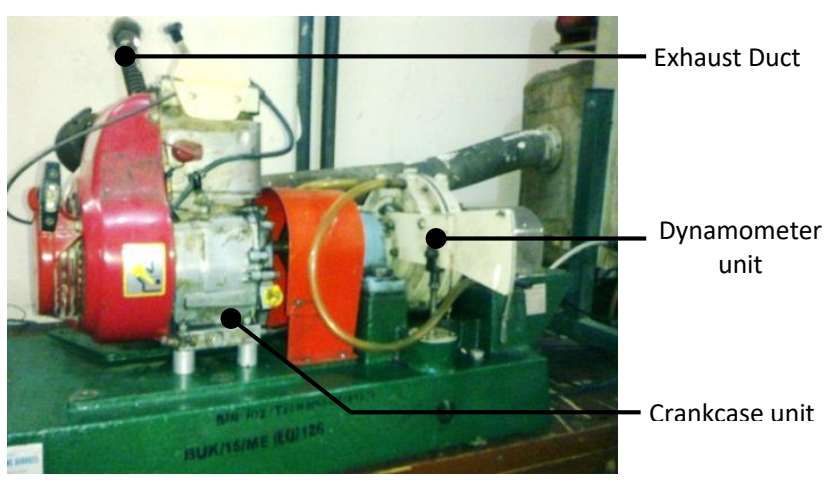

(a) TD110/G24.

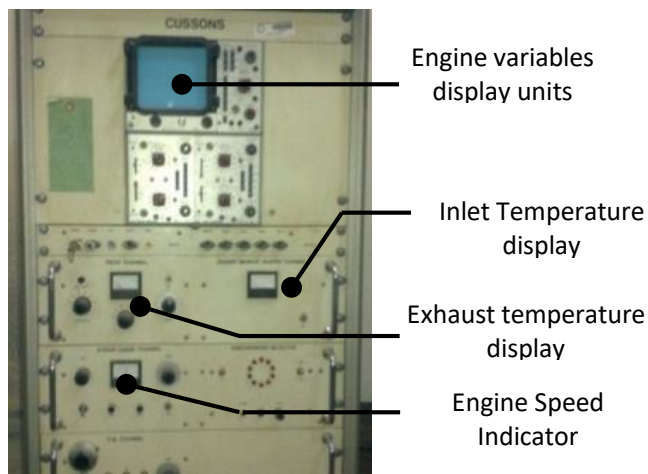

(b) P8150

Figure 3. Experimental Set up: (a) Engine unit; (b) Data aquitition unit for P8150.

The facility in Figure 3 is a dual spark ignition engine test bench - as it can be cannibalised to take a two-stroke arrangement. The variable inputs to the engine model are: throttle angle, manifold pressure, cylinder swept volume and engine speed. The ambient condition used for experiments and simulation were: pressure of $99.85 \mathrm{kPa}$ to $101.4 \mathrm{kPa}$, and temperature $-28{ }^{\circ} \mathrm{C}$ to $32{ }^{\circ} \mathrm{C}$. The key expected outputs from the model were air mass flow rate into the inlet manifold, air mass flow rate into the cylinder, and throttle valve flow area. The analysis of the differential mass between the manifold and the crankcase/cylinder was sectioned into three parts - flow area, differential manifold pressure and mass flow rate. The following basic steps were taken.

i. Flow area: the geometric size of the spindle diameter d, manifold diameter D and manifold length $\mathrm{L}$ were established, with the initial condition $\varphi_{o}=5^{\circ}$ to prevent stalling. Equations (5) and (6) were used to evaluate the area $A_{n+1}$ from $\varphi=\varphi_{o}: 1^{o}: \varphi_{n}$ as input.

ii. Differential Pressure: the manifold initial pressure condition is taken as $P_{m(n=0)}$ $=10140 \mathrm{~N} / \mathrm{m}^{2}$, while $\mathrm{P}_{\mathrm{m}(\mathrm{n}+1)}$ is evaluated as:

iii. $\quad p_{m(n+1)}=p_{m(n)}+\Delta t *\left(A(\varphi) * p_{a} C_{d} *\left(R T_{m} / V_{m}\right)^{1 / 2} *\left(2 / \beta R T_{a}\right)^{1 / 2} *\right.$

$$
\left.\left[\left(p_{m(n)} / p_{a}\right)^{\alpha}-\left(p_{m(n)} / p_{a}\right)^{\xi}\right]^{1 / 2}-c_{1} \eta_{d} \omega p_{m(n)}\right)
$$

iv. Mass flow rate: This has two components - mass flow into the manifold and mass flow into the crankcase/cylinder. With input from the instantaneous projected flow area, $\mathrm{P}_{\mathrm{m}(\mathrm{n}+1)}$ and other indicated constants, the two flow rates were established using Equations (3) and (7). With the flow area and engine speed fixed, the net rate of flow of air-fuel over a cycle will be in terms of manifold differential pressure only. A time step of $0.0001 \mathrm{~s}$ was utilised between $\mathrm{t}=0$ and $\mathrm{t}=0.05 \mathrm{~s}$.

v. The open down period of the intake port ODP was obtained in seconds from the following relation: 


$$
O D P=\Delta \theta / 360 * 60 / N=\Delta \theta / 6 N
$$

\section{RESULTS AND DISCUSSION}

\section{In-flow Aperture}

Figure 4 shows the output area as a response to variation in throttle angle from $0^{\circ}$ to $90^{\circ}$. Between $0^{\circ}$ and $25^{\circ}$, the cross-sectional flow area's response was not linear due to the high inertia and drag force imposed by the crescent-like shape of the aperture. As the angle was increased between $30^{\circ}$ and $75^{\circ}$, the response became almost linear. All the tests conducted were established within this region to allow investigation of other flow variables, while area/throttle valve can be quickly adjusted and proportionately. As the throttle angle was increased further to slightly over and beyond $80^{\circ}$, the flow area became erratic and unstable. This is indicated as a gully in the simulation result (blue line). It was not significantly noticed in experimental result due to the fact that at almost wide-open-throttle (WOT), $>80^{\circ}$, the engine speed is very high, thus superimposing its frequency over the deviation of event in a cycle. The result is required to identify the linear part of the throttle operation. The values of the coefficients of discharge, $\mathrm{C}_{\mathrm{d}}=$ 0.58 for simulation and 0.53 for experimentation indicated that there was a high reduction in flow across the throttle plate.

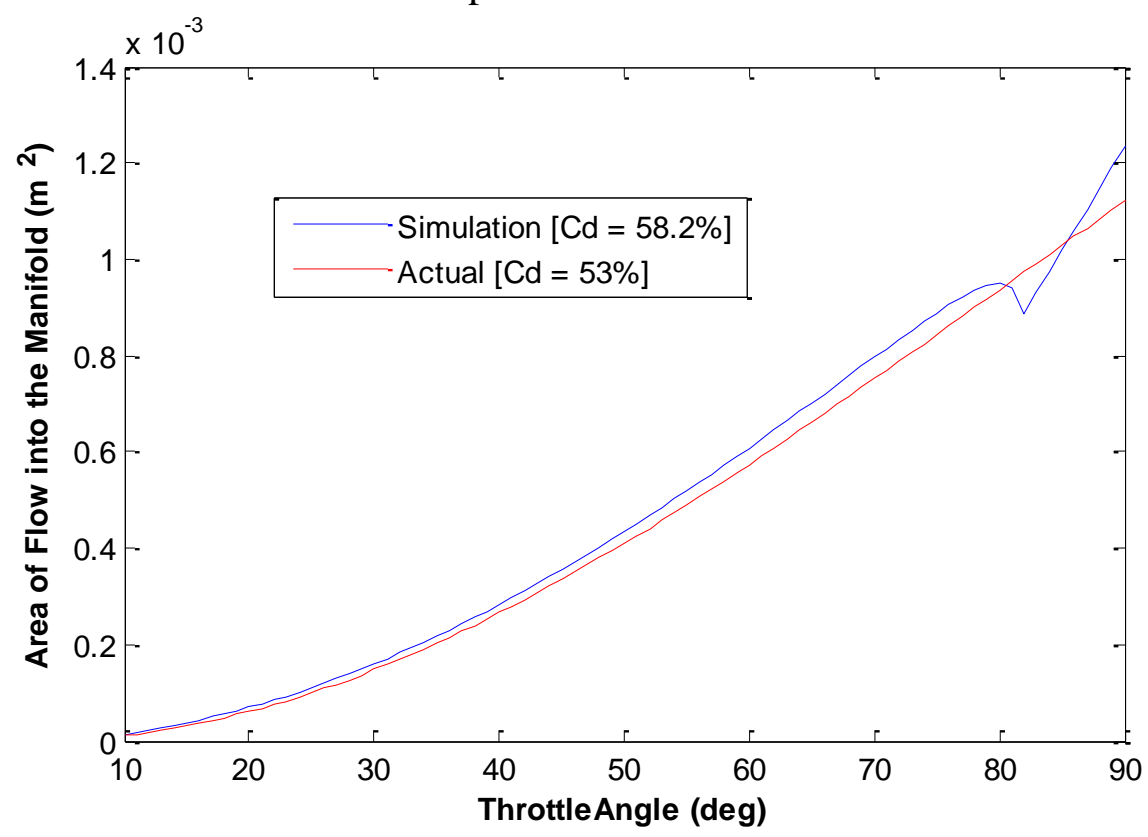

Figure 4. Area of flow in $\mathrm{m}^{2}$ with respect to throttle angular displacement in degree.

\section{Variation of Differential Pressure with Engine Speed}

Table 1 presents the time-lag and overlap over of a cycle for pressures $\leq 100 \mathrm{kPa}$. At different engine speeds in rpm in column 1, the cycle periods in seconds were established in column 2 as 60/N. For a constant intake port open down coverage of $96^{\circ}$, the corresponding open down period in seconds for each engine speed was obtained using Eq. (11) and the result is presented in column 3. The time $t$ (s) for pressure to stabilise or attain equilibrium where the quantity demanded and supply are equal at each engine speed was obtained from the graphs of Figures 6,8 and 10, which is at most 
approximately $0.0125 \mathrm{~s}$. This unified value is considered for all speeds because of the narrow power band with the nature of the two-stroke SIE. For each speed, the ratio of difference between $\mathrm{ODP}^{\mathrm{A}}$ and $\mathrm{ST}^{\mathrm{B}}$ and the cycle period $\mathrm{P}$, that is: $\left(\mathrm{ODP}^{\mathrm{A}}-\mathrm{ST}^{\mathrm{B}}\right) / \mathrm{P}_{\text {gives }}$ the fraction of time loss of supply in each cycle. The fraction is used to establish time relation of demand, supply and utilisation between consecutive cycles.

Table 1. Lag Time and Overlap Cycle Analysis for $10 \mathrm{kPa}$ manifold pressure.

\begin{tabular}{cccccccc}
\hline 1 & 2 & 3 & 4 & 5 & 6 & 7 & 8 \\
\hline $\begin{array}{c}\text { Engine } \\
\begin{array}{c}\text { Speed, N } \\
{[\mathrm{rpm}]}\end{array}\end{array}$ & $\begin{array}{c}\text { Cycle } \\
\text { Period, } \\
\mathrm{P}[\mathrm{sec}]\end{array}$ & $\begin{array}{c}\mathrm{ODP}^{\mathrm{A}} \\
{\left[{ }^{\mathrm{o}}\right]}\end{array}$ & $\begin{array}{c}\mathrm{ODP}^{\mathrm{A}} \\
{[\mathrm{sec}]}\end{array}$ & $\begin{array}{c}\mathrm{ST}^{\mathrm{B}} \\
{[\mathrm{sec}]}\end{array}$ & $\begin{array}{c}\mathrm{TL}= \\
(\mathrm{ODP}-\mathrm{ST}) \\
{[\mathrm{s}]}\end{array}$ & $\begin{array}{c}\text { TLR } \\
= \\
\mathrm{TD} / \mathrm{P}\end{array}$ & Remarks \\
\hline 1000 & 0.060 & 96 & 0.0160 & 0.0125 & 0.0035 & 0.06 & OK $^{\mathrm{C}}$ \\
2000 & 0.030 & 96 & 0.0080 & 0.0125 & -0.0045 & -0.15 & Lag $^{\mathrm{D}}$ \\
3000 & 0.020 & 96 & 0.0053 & 0.0125 & -0.0072 & -0.36 & Lag \\
4000 & 0.015 & 96 & 0.0040 & 0.0125 & -0.0085 & -0.57 & Lag \\
5000 & 0.012 & 96 & 0.0032 & 0.0125 & -0.0093 & -0.78 & Lag \\
6000 & 0.010 & 96 & 0.0026 & 0.0125 & -0.0098 & -0.98 & Lag \\
7000 & 0.009 & 96 & 0.0022 & 0.0125 & -0.0102 & -1.19 & Overlap $^{\mathrm{E}}$ \\
\hline
\end{tabular}

${ }^{\mathrm{A}} \mathrm{ODP}=$ Open down period of intake port in degree and seconds

${ }^{\mathrm{B}} \mathrm{ST}=$ Unified average time in seconds for pressure gradient to become zero from point A to B (Fig. 2)

${ }^{\mathrm{C}} \mathrm{OK}=$ Implies that the required quantity of charge was delivered before the closure of inlet port.

${ }^{\mathrm{D}} \mathrm{Lag}=$ Implies that the supply time is greater than the time available for delivery in the same cycle.

${ }^{\mathrm{E}}$ Overlap = Implies that the supply time is greater than the delivery time available from at least two cycles.

From Table 1, the ratio of time loss, TLR is obtained from time loss, TL $=(\mathrm{ODP}$ - ST) of supply per cycle in seconds to the stabilising time, ST in seconds as given in column 7. It reduces linearly with increases in engine speed as separately shown in Figure 5. It shows three regions of speed operations: adequate, lagging with the cycle and lagging over a cycle (overlap). At a low speed of $1000 \mathrm{rpm}$, the time loss ratio was in a positive zone with a value of +0.06 , implying that the required quantity of charge was delivered before the closure of inlet port. As the speed was increased - from higher values of 2000 to $6000 \mathrm{rpm}$, the ratio of time loss changed to negative: $-0.15, \ldots,-0.98$, indicating time-lag zone across the speed. At an extremely high speed of $7000 \mathrm{rpm}$, the ratio was not only negative but also less than -1 , showing that the current cycle supply will only be available in next cycle - hence, a huge supply overlap.

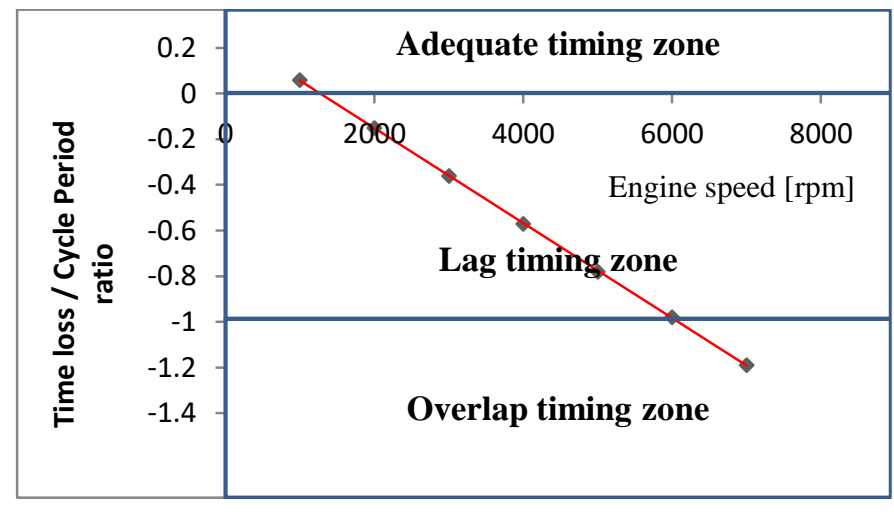

Figure 5. Time loss to stability ratio against engine speed $-\mathrm{rpm}$. 


\section{Manifold Differential Pressure and Mass Flow Rate}

Manifold differential pressure is the deference in pressure that is responsible for the difference in charge delivered (or supplied) to the crankcase/cylinder and that required (demanded) for maximum power output in a stoichiometric operating condition during the open down period of the intake port. Figures 6 to 11 give the results of the mass flow rate required (demanded) in blue colour, mass flow rate delivered (supplied) in red colour and differential mass in black colour; for $45^{\circ}, 60^{\circ}$ and $75^{\circ}$ throttle angles - within the linear range of throttle operation, at engine speeds of 1,000, 4,000 and 7,000 rpm, respectively.

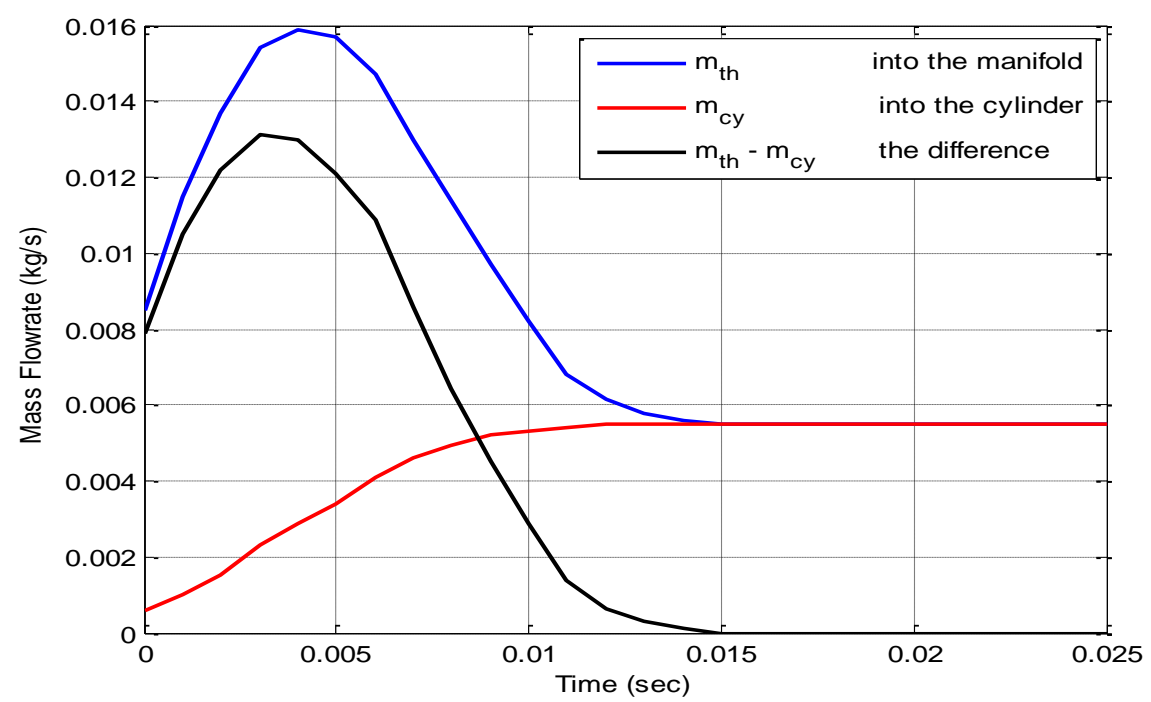

Figure 6. Manifold mass flow rate against time for $\mathrm{N}=1000 \mathrm{rpm}$ and $\psi=45^{\circ}$.

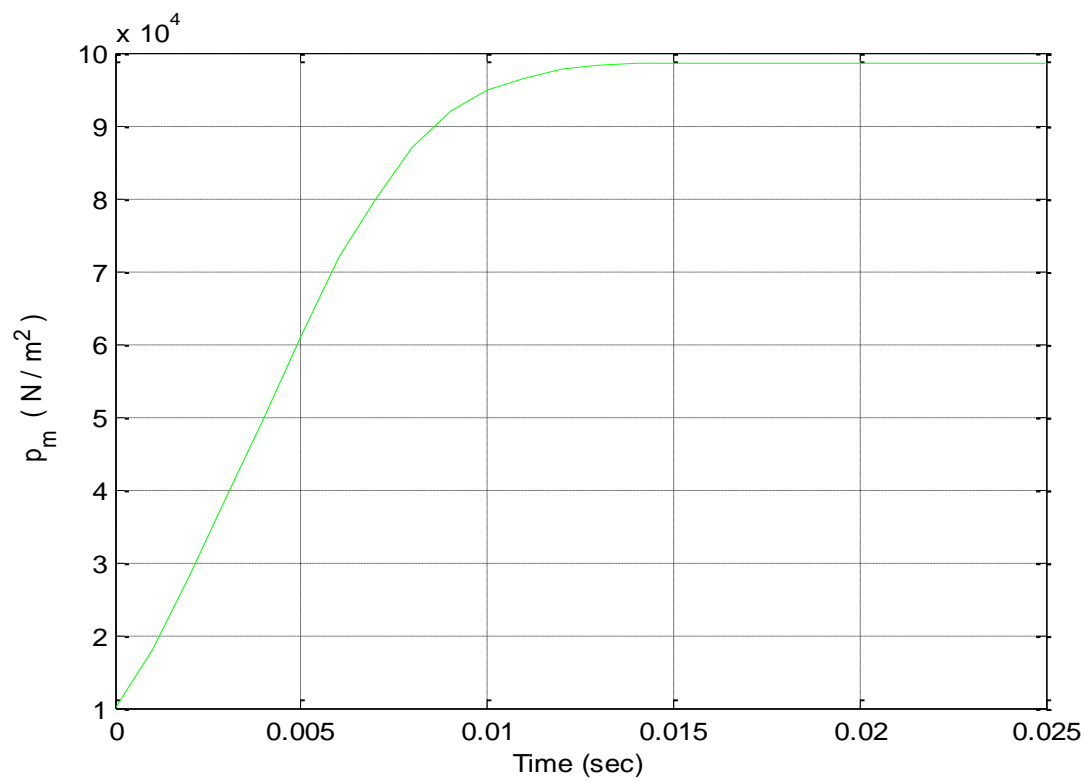

Figure 7. Manifold pressure against time for $\mathrm{N}=1000 \mathrm{rpm}$ and $\psi=45^{\mathrm{O}}$.

At the low engine speed of $1,000 \mathrm{rpm}$, throttle angle of $45^{\circ}$ and an initial manifold pressure of $10,140 \mathrm{~N} / \mathrm{m}^{2}$, as shown in Figure 7, there is steady rise in manifold pressure from an intake value of $10140 \mathrm{~N} / \mathrm{m}^{2}$ to $80,000 \mathrm{~N} / \mathrm{m}^{2}$ within $7.5 \mathrm{~ms}$ before reaching its maximum value of $98 \mathrm{kN} / \mathrm{m}^{2}$ at $12.5 \mathrm{~ms}$. Beyond this time, no further 
change in pressure was observed, thus the differential pressure becomes zero. The maximum mass transfer rate (instantaneous maximum demand - in blue) within this period was $0.0165 \mathrm{~kg} / \mathrm{s}$ occurring at about $4 \mathrm{~ms}$ as shown in Figure 6. The corresponding mass flow into the crankcase at the same time $(4 \mathrm{~ms})$ was only 0.0013 $\mathrm{kg} / \mathrm{s}$ (supply - in red), leaving a difference of $0.0135 \mathrm{~kg} / \mathrm{s}$ (instantaneous differential loss - in black), representing about $81.8 \%$ of engine demand. The equilibrium time, ET, is $15 \mathrm{~ms}$ and the equilibrium quantity demanded and supplied is $0.0055 \mathrm{~kg} / \mathrm{s}$.

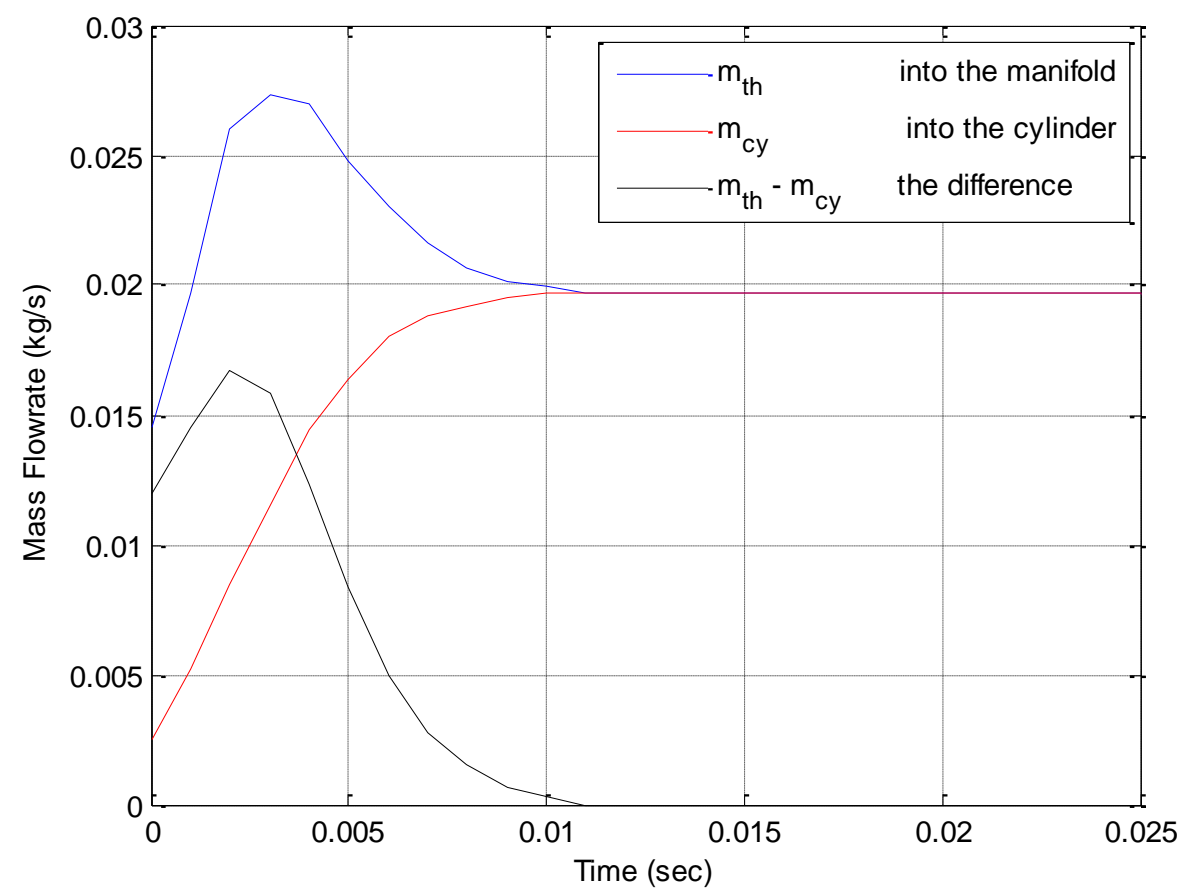

Figure 8. Manifold mass flow rate against time for $\mathrm{N}=4000 \mathrm{rpm}$ and $\psi=60^{\mathrm{O}}$

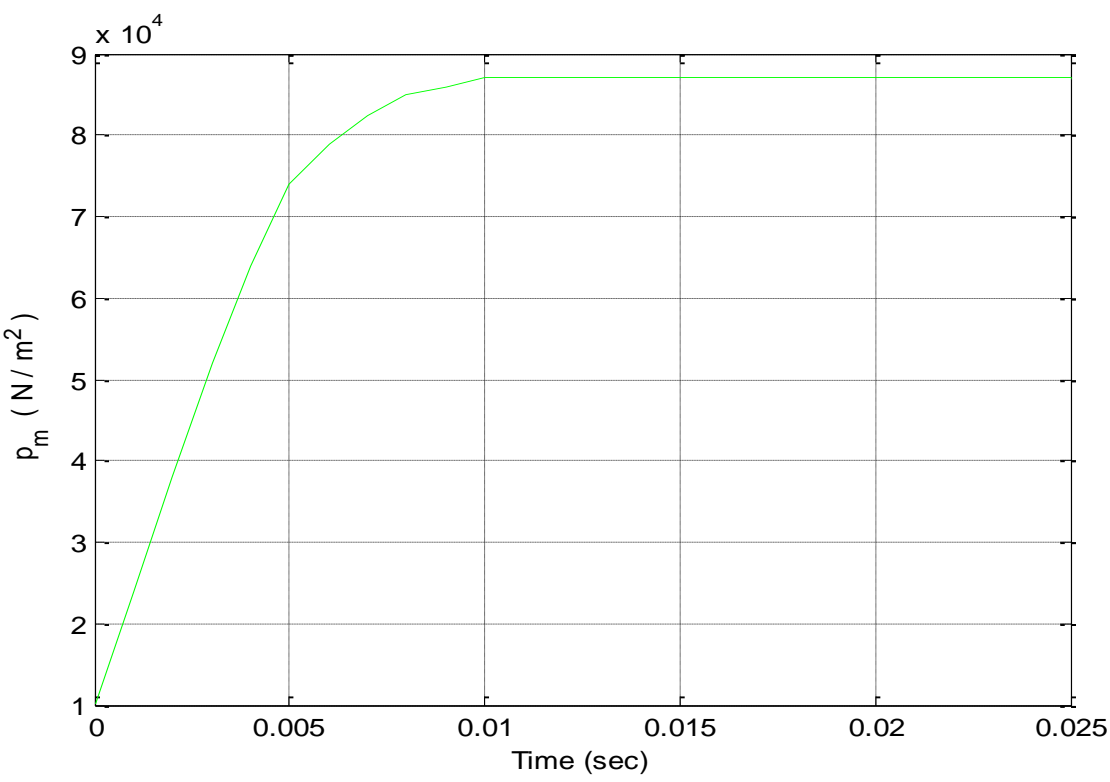

Figure 9. Manifold pressure against time for $\mathrm{N}=4000 \mathrm{rpm}$ and $\psi=60^{\circ}$

As the engine speed was increased to $4,000 \mathrm{rpm}$ with a throttle angle of $60^{\circ}$ and the same initial manifold intake pressure of $10140 \mathrm{~N} / \mathrm{m}^{2}$ as shown in Figure 9, the 
pressure also increased steadily to a value of $74 \mathrm{~N} / \mathrm{m}^{2}$ within $5 \mathrm{~ms}$ and finally reached its maximum value of about $87 \mathrm{kN} / \mathrm{m}^{2}$ at $10 \mathrm{~ms}$. The response of mass flow rate to this various in pressure is given in Figure 8. The maximum demand (in blue) within this period was $0.0275 \mathrm{~kg} / \mathrm{s}$ which occurred at about $3 \mathrm{~ms}$, while the corresponding supply (in red) at the same time was only $0.0125 \mathrm{~kg} / \mathrm{s}$. The differential mass (charge loss) was $0.0150 \mathrm{~kg} / \mathrm{s}$, representing about $54.5 \%$ of demand. At equilibrium time, ET, the quantity supplied was equal to that demanded at approximately $0.0195 \mathrm{~kg} / \mathrm{s}$ which occurred later at $11 \mathrm{~ms}$.

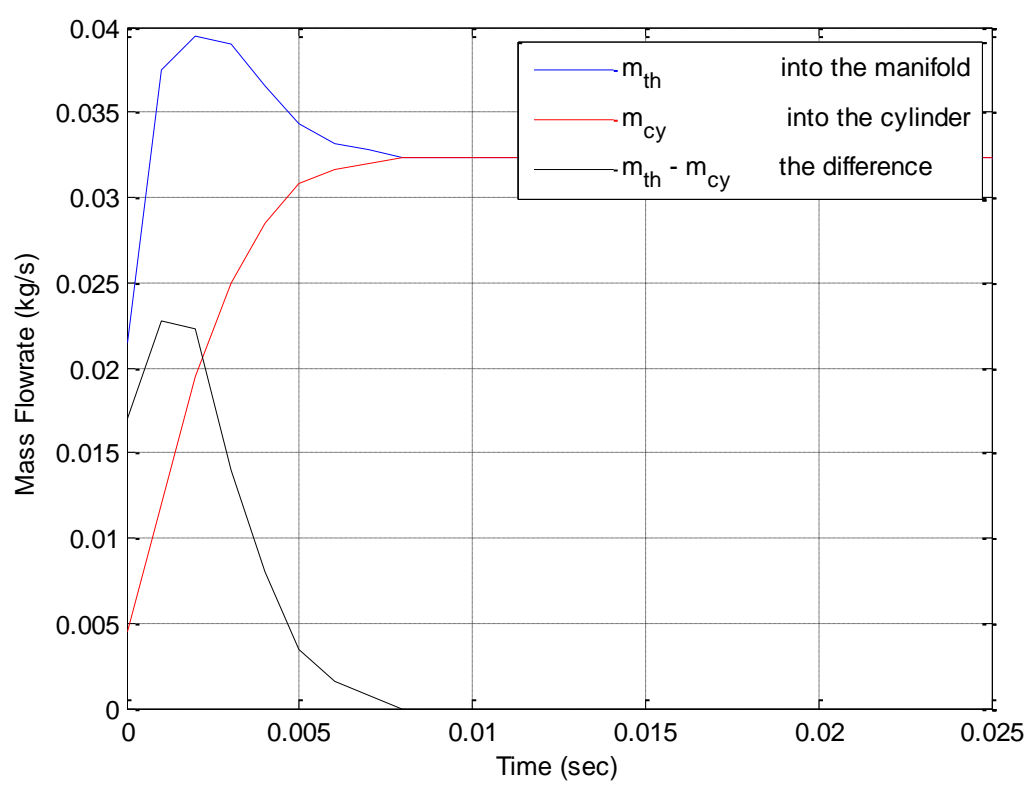

Figure 10. Manifold mass flow rate against time for $\mathrm{N}=7000 \mathrm{rpm}$ and $\psi=75^{\circ}$

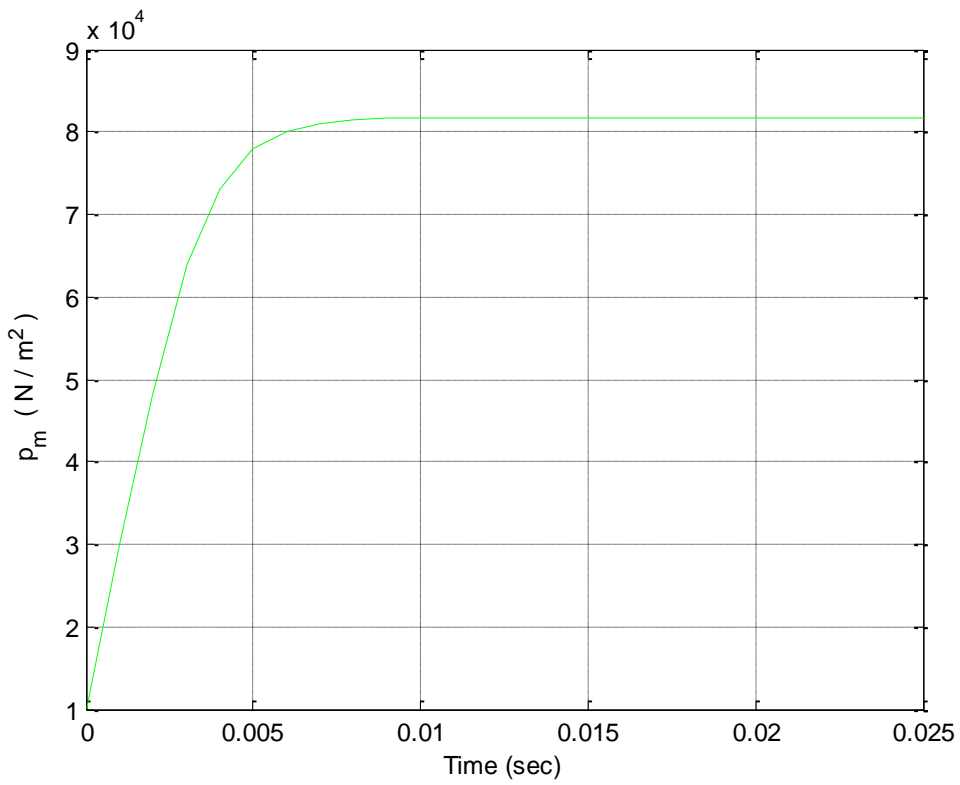

Figure 11. Manifold pressure against time for $\mathrm{N}=7000 \mathrm{rpm}$ and $\psi=75^{\mathrm{O}}$

In Figure 11, at $75^{\circ}$ throttle angle, high speed of 7,000 rpm and the same initial pressure of $10140 \mathrm{~N} / \mathrm{m}^{2}$, the pressure rose steadily to about $3 \mathrm{~ms}$ and gradually 
increased to its maximum value of $8.2 \mathrm{~N} / \mathrm{m}^{2}$ in $8 \mathrm{~ms}$. Figure 10 presents the corresponding mass transfer variations with respect to pressure growth. The maximum demand (in blue) was $0.039 \mathrm{~kg} / \mathrm{s}$ which occurred at $2.5 \mathrm{~ms}$, while the corresponding supply was only about $0.020 \mathrm{~kg} / \mathrm{s}$, resulting in a peak difference of $0.019 \mathrm{~kg} / \mathrm{s}$ within $1.5 \mathrm{~ms}$. This represents a gap of $48.7 \%$. At equilibrium time, ET, the quantity supplied was equal to that demanded - approximately $0.0325 \mathrm{~kg} / \mathrm{s}$ which occurred later at $8 \mathrm{~ms}$.

From these results, it can be summarised that:

i. Mass loss increases with engine speed - from $0.0135 \mathrm{~kg} / \mathrm{s}$ at $1,000 \mathrm{rpm}$ through $0.015 \mathrm{~kg} / \mathrm{s}$ at $4,000 \mathrm{rpm}$ to $0.019 \mathrm{~kg} / \mathrm{s}$ at $7,000 \mathrm{rpm}$. The trend is shown to be a quadratic relationship as shown in Figure 12. The implication of this is that the port window remains constant while the time available for mass transfer reduces with increases in engine speed. This situation results in the earlier closure of the ports at higher speeds, hence the escalation of mass loss as speed increases.

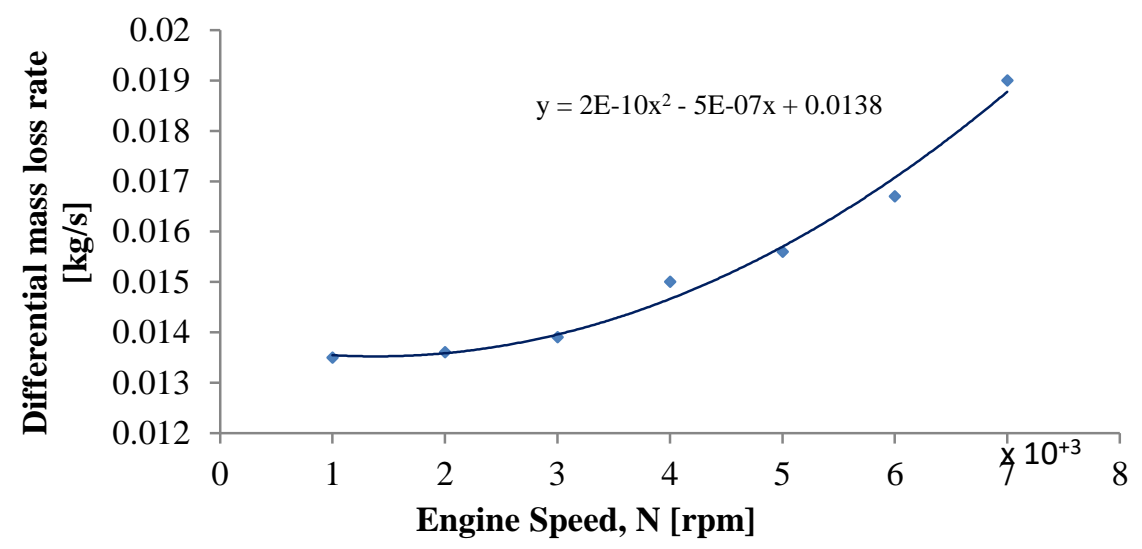

Figure 12. Differential mass loos rate against engine speed.

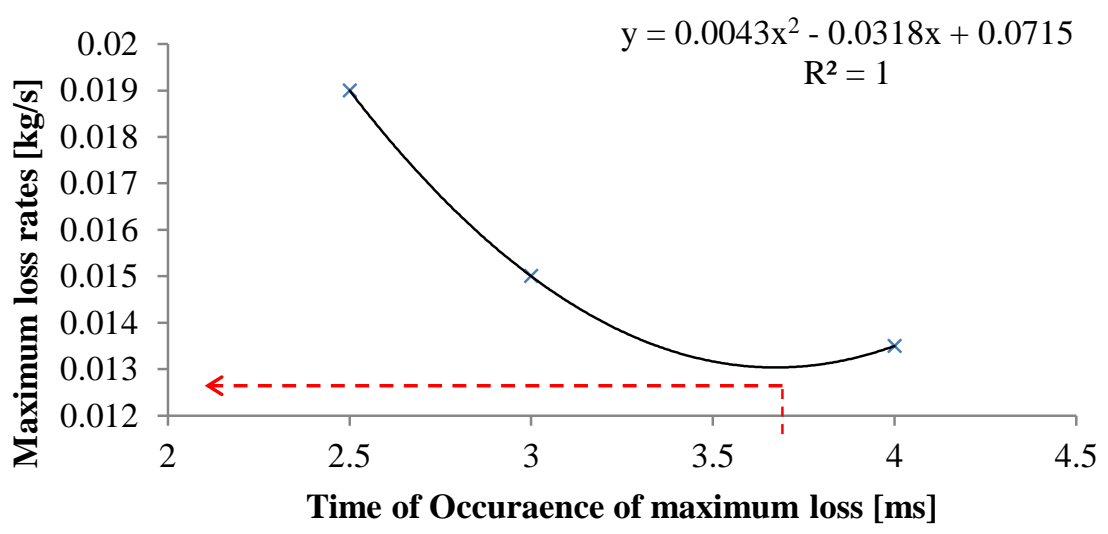

Figure 13. Variation of maximum loss rate against time of occurrence

ii. The time of occurrence of instantaneous mass lost is inversely related to the mass loss as displayed in Figure 13. The minimum possible loss is $0.013 \mathrm{~kg} / \mathrm{s}$ occurring at $3.7 \mathrm{~ms}$.

iii. The maximum attainable pressure reduces with increase in speed and thus, its ramming effect. After the linear pressure rises in each case as shown in Figures 7, 9 and 11, the time required for the pressure to reach their maximum values is the 
same at all speeds: $5 \mathrm{~ms}$. Thus, the intake and ramming activities of the flow charge is predominantly between $0 \mathrm{~ms}$ and $7.5 \mathrm{~ms}$. It is within this range that a huge quantity of gas is lost because the open down periods at all speeds are inadequate except that of 1,000 rpm and marginally 2,000 rpm.

The results show that there is a huge loss in two-stroke SIEs which increases with engine speed, while the differential pressure producing the loss falls. At higher speeds, maximum flow rate loss tends to occur earlier than at lower speeds. With this, the loss due to time lag and overlap are easily estimated and properly compensated for.

\section{CONCLUSIONS}

To improve the air/charge demand of a spark ignition engine, the manifold differential pressure can be used to estimate the difference between the engine charge requirement (demand) and the quantity delivered (supply) for combustion. This gap can be evaluated against engine speed to estimate the time lag of supply, and at times, the cycle overlap. This may be used to regulate the air supply reaching the cylinder with respect to the predetermined fuel supply via the air/fuel ratio. The paper presents the use of the manifold differential pressure to model the air intake and its relationship with the rate of fuel demand in terms of the mixture flow rate, physical parameters of the manifold, and the projected area at manifold and crankcase in-ports. Overall, the research uses the manifold differential pressure to establish instantaneous difference in the demand and utilisation of the working fluid. The results show that the in-charge demand of a twostroke engine is never met partly due to the intake manifold constraints. At low engine speeds, there is enough time for the flow to reach the crankcase/cylinder, but over $80 \%$ of the demand is lost to pathway constraints while at high speeds, losses are majorly due to time lag and cycle overlaps due to the limited time for supply chain operations. On average, at least about 55\% of the charges demanded in a two-stroke engine are always not available - resulting in low power output, poor fuel economy and high emissions.

\section{ACKNOWLEDGEMENTS}

The authors are indebted to Faculty of Technology, Bayero University Kano for its Lab facilities and Engr. Salih A. for coordinating the engine bench work on TD110/G24.

\section{REFERENCES}

[1] Rajput RK. A Textbook of Internal Combustion Engines. 3rd ed. New Delhi: Laxmi Publications Pvt Ltd2010.

[2] Kazuei I. Effect of Variable Intake Manifold on Engine Performance. Subaru Automobile Quarterly Magazine. New York2009.

[3] Aminu J. Pollution by two-stroke engines. In: The Nigerian conference on clean air, clean fuels and vehicles; 2012.

[4] Jennings BGJaG. Two-Stroke Tuner's Handbook2007.

[5] Wani MM, Mursaleen M, Parvez S. Investigations on a Two Stroke Cycle Spark Ignition Engine Using Gasoline Direct Injection. Energy and Power. 2012;2:116-22. 
[6] Jaichandar S, Annamalai K. Jatropha oil methyl ester as diesel engine fuel-an experimental investigation. International Journal of Automotive and Mechanical Engineering. 2016;13:3248.

[7] Rostami S, Ghobadian B, Kiani MKD. Effect of the injection timing on the performance of a diesel engine using Diesel-Biodiesel blends. International Journal of Automotive and Mechanical Engineering. 2014;10:1945.

[8] Adam IK, Aziz ARA, Yusup S. Determination of diesel engine performance fueled biodiesel (rubber seed/palm oil mixture) diesel blend. International Journal of Automotive and Mechanical Engineering. 2015;11:2675.

[9] Moskwa JJ, Hedrick JK. Automotive engine modeling for real time control application. American Control Conference, 1987: IEEE; 1987. p. 341-6.

[10] Taglialatela-Scafati F, Cesario N, Cassese P. Method and device for estimating the inlet air flow in a combustion chamber of a cylinder of an internal combustion engine. Google Patents; 2007.

[11] Arcoumanis C, Whitelaw J, Flamang P. Flow in the inlet manifold of a production diesel engine. Proceedings of the Institution of Mechanical Engineers, Part C: Mechanical Engineering Science. 1989;203:39-49.

[12] Voser C, Dönitz C, Ochsner G, Onder C, Guzzella L. In-cylinder boosting of turbocharged spark-ignited engines. Part 1: Model-based design of the charge valve. Proceedings of the Institution of Mechanical Engineers, Part D: Journal of Automobile Engineering. 2012;226:1408-18.

[13] Shinde PA. Research and optimization of intake restrictor for Formula SAE car engine. International Journal of Scientific and Research Publications. 2014;4:1.

[14] Zsiga N, Voser C, Onder C, Guzzella L. Intake manifold boosting of turbocharged spark-ignited engines. Energies. 2013;6:1746-63.

[15] Postma M, Nagamune R. Air-fuel ratio control of spark ignition engines using a switching LPV controller. IEEE Transactions on Control Systems Technology. 2012;20:1175-87.

[16] Zhai Y-j, Sun Y, Qian K-j, Lee S-h. A multi-input and multi-output design on automotive engine management system. Journal of Central South University. 2015;22:4687-92.

[17] Nayak S, Mishra P. Emission from a dual fuel operated diesel engine fuelled with Calophyllum Inophyllum biodiesel and producer gas. International Journal of Automotive \& Mechanical Engineering. 2017;14.

[18] Azad AK, Rasul M, Giannangelo B, Islam R. Comparative study of diesel engine performance and emission with soybean and waste oil biodiesel fuels. International Journal of Automotive and Mechanical Engineering. 2015;12:2866.

[19] Rizvi MA, Raza Q, Bhatti AI, Zaidi S, Khan M. Modeling and Simulation of SI Engines for Fault Detection. Internal Combustion Engines: InTech; 2012.

[20] Lawal MN. Numerical and Experimental Study of Scavenging Process in TwoStroke SIE that Utilize Premix Fuel Blends. Federal University of Technology. 2015.

[21] Hendricks E. Engine modelling for control applications: A critical survey. Meccanica. 1997;32:387-96.

[22] Polonsk MM. Complex Systems Simulation Using MATLAB/SIMULINK, The Technology Interface. 2000. 